\title{
Características dos serviços públicos de saúde mental (Capsi, Capsad, Caps III) do estado de Santa Catarina
}

\author{
Characteristics of public mental health services (Capsi, Capsad, Caps \\ III) of the Santa Catarina State
}

Aline Batista Bernardi1, Lilia Aparecida Kanan²

RESUMO O artigo apresenta as características de estrutura física, de recursos humanos e de atendimentos ofertados aos adolescentes com transtornos decorrentes do uso de álcool e outras drogas nos serviços públicos de saúde mental do estado de Santa Catarina. Estudo de natureza qualiquantitativa e descritiva. Das 21 equipes de profissionais dos serviços existentes no estado, 19 participaram do estudo. Os dados foram coletados mediante questionário on-line e organizados em categorias definidas a priori. Ao final, conclui-se que é premente a ampliação dos equipamentos da rede de saúde mental para atendimento de crianças e adolescentes usuários de drogas, com base na atenção integral e intersetorial de cuidado.

PALAVRAS-CHAVE Saúde mental; Saúde pública; Adolescente; Transtornos relacionados ao uso de substância.

\begin{abstract}
The article presents the characteristics of physical structure, human resources and care offered to adolescents with disorders resulting from the use of alcohol and others drugs in the public mental health services of the Santa Catarina State. It is a qualitative, quantitative and descriptive study. Of the 21 professional teams of existing services in the state, 19 participated in the study. Data were collected through online questionnaire and organized into defined categories. At the end, it is concluded that it is urgent the expansion of Mental Health network equipment for the care of children and adolescents drug users, based on the full attention and intersectoral care.
\end{abstract}

KEYWORDS Mental health; Public health; Adolescent; Substance-related disorders.

\footnotetext{
1 Universidade do Planalto Catarinense (Uniplac), Programa de PósGraduação stricto sensu em Ambiente e Saúde. Saúde - Lages (SC), Brasil. alinebernardi@hotmail.com

2 Universidade do Planalto Catarinense (Uniplac), Programa de PósGraduação stricto sensu em Ambiente e Saúde. Saúde - Lages (SC), Brasil. lilia.kanan@gmail.com
} 


\section{Introdução}

O uso de drogas na adolescência afeta a cognição, a capacidade de julgamento, o humor e as relações interpessoais, aspectos que, frequentemente, já se encontram em desenvolvimento nesse período e que podem ser comprometidos pelo uso de drogas. Pinsky e Bessa (2012, P. 11) asseveram que a adolescência é uma fase de mudanças, "época de grandes transformações, de descobertas, de rupturas e de aprendizados". Os autores afirmam que é em decorrência dessas transformações que essa se torna uma fase de medos e instabilidades, que podem ocasionar alterações de comportamentos, oscilando entre demonstrações de agressividade, agitação e impulsividade ou tédio, sonolência e insatisfação com a vida no geral. Depreende-se, assim, que a fase da adolescência necessita de cuidado, amparo e proteção, pois, além da transformação para um corpo adulto, existe uma maturação emocional a ser considerada.

A adolescência, além de ser um período de transições, também evidencia a necessidade de integração social, busca de autoafirmação, construção da identidade sexual e da independência. Com relação à motivação para o uso e a dependência de drogas psicoativas, Silva e Mattos (2012) ponderam que os circuitos cerebrais envolvidos na motivação são os responsáveis pela impulsividade e pela tomada de decisões, áreas, geralmente, em desenvolvimento na adolescência. Os autores afirmam que, se ocorrer experimentação de drogas psicoativas nessa fase, recebendo o adolescente cuidado, amparo e proteção pela rede familiar e social, possivelmente, o uso de drogas será interrompido com a maturidade.

Em 2012, foi realizada a Pesquisa Nacional de Saúde do Escolar (PeNSE), pelo Instituto Brasileiro de Geografia e Estatística (IBGE), que investigou os fatores de risco e proteção à saúde dos adolescentes, tendo como população os escolares do $9^{\circ}$ ano do ensino fundamental. No que se refere ao uso de drogas, os dados da PeNSE 2012 mostraram que 66,6\% dos escolares já haviam experimentado bebida alcoólica, sendo esse indicador maior na região Sul do País (76,9\%). Destaca-se que 21,8\% dos escolares já tiveram algum episódio de embriaguez na vida (IBGE, 2012).

No tocante ao uso de drogas ilícitas, tais como maconha, cocaína, crack, cola, loló, lança perfume, ecstasy, evidenciou-se que $7,3 \%$ dos escolares já haviam feito uso. Considerando-se, exclusivamente, os escolares que usaram drogas ilícitas alguma vez na vida, 34,5\% utilizaram maconha, e $6,4 \%$ usaram crack. Deste modo, o uso de drogas na adolescência torna-se um problema de saúde pública, uma vez que seu consumo abusivo tem aumentado ao longo dos anos.

No que se refere ao atendimento desses adolescentes, Pereira (2012) assegura que se trata de uma demanda que exige reflexões clínicas constantes e chama a atenção para a consolidação da política voltada ao sistema de garantia de direitos das crianças e dos adolescentes.

No Brasil, há significativo aparato legal que converge para a obrigatoriedade de que o Centro de Atenção Psicossocial (Caps) se constitua como um serviço substitutivo que ofereça atividades terapêuticas e atendimento clínico em regime de atenção diária, ou seja, o Caps extrapola seu uso para consultas e obtenção de medicamentos, evitando, desse modo, as internações em hospitais psiquiátricos. Esse processo chama-se Clínica Ampliada, que está sendo reorientada nas práticas de atenção psicossocial, o que provoca mudanças nos modos tradicionais de compreensão e de tratamento dos transtornos mentais.

Os Caps, regulamentados pela Portaria n. ${ }^{\circ}$ 336/2002 (BRASIL, 2002B), devem ser compostos por uma equipe multiprofissional, e esses profissionais devem trabalhar com perspectiva interdisciplinar, sendo responsáveis pela unidade durante todo o seu período de funcionamento, o que inclui criar uma ambiência terapêutica acolhedora. Os Caps podem se constituir em 5 modalidades: Caps I, Caps II e Caps III, 
diferenciando-se apenas no que se refere à ordem crescente de porte/complexidade e abrangência populacional. E outros 2 serviços específicos de atenção psicossocial: Capsi (Criança e Adolescente), voltado à atenção psicossocial para atendimentos de crianças e adolescentes; e Capsad (Álcool e outras Drogas), responsável pela atenção psicossocial de pessoas com transtornos decorrentes de uso e dependência de substâncias psicoativas.

A Portaria n. ${ }^{\circ} 3.088 / 2011$ propõe que os adolescentes com necessidades decorrentes do uso de crack, álcool e outras drogas sejam atendidos nos diversos pontos de atenção da Rede de Atenção Psicossocial (BRASIL, 2011). Entendese, assim, que, por critério clínico, no caso de abuso de drogas, deveriam ser atendidos em um Centro de Atenção Psicossocial. Todavia, o Ministério da Saúde não definiu de forma clara qual Caps possui atribuição exclusiva para atendimento de crianças e adolescentes com transtornos mentais decorrentes do uso de drogas psicoativas, atribuindo a responsabilidade tanto aos Capsi quanto aos Capsad.

Ainda, atribui ao Caps I (que deve ser implantado em municípios com população entre 20.000 e 70.000 habitantes) responsabilidade com relação ao atendimento de crianças e adolescentes (BRASIL, 2011), sendo, portanto, necessário que cada município defina o fluxo mais adequado às necessidades da população.

A inclusão tardia da saúde mental infantojuvenil na agenda das políticas de saúde mental pode ser atribuída a diversos fatores. De acordo com Couto, Duarte e Delgado (2008), alguns exemplos que podem ser destacados são: a extensa e variada gama de problemas relacionados à saúde mental da infância e da adolescência; a complexidade da avaliação diagnóstica e situacional; a dificuldade de encontrar estudos sistematizados sobre as consequências dos transtornos mentais originados na infância e na adolescência sobre a vida adulta; poucas evidências empíricas de qualidade sobre a eficácia e a efetividade de tratamentos para transtornos mentais infantis; e a dificuldade de inclusão da saúde mental infantil no campo da saúde pública.

Couto, Duarte e Delgado (2008, P. 392) asseveram que

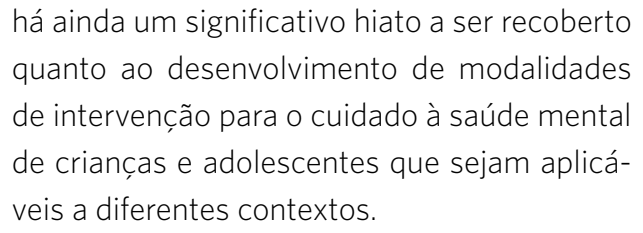

Esse entendimento vai ao encontro de Espinola (2013), quando afirma que a realidade complexa vivenciada por todos os envolvidos no processo de atenção de adolescentes com transtornos decorrentes do uso de drogas estimula os profissionais e pesquisadores no sentido de observar, investigar, analisar as mudanças das práticas de atenção e cuidado oferecidas aos adolescentes usuários de drogas psicoativas e a seus familiares nos serviços de saúde.

Neste artigo, objetiva-se apresentar as características da estrutura física, de recursos humanos e de atendimentos ofertados aos adolescentes com transtornos decorrentes do uso de drogas nos serviços de saúde mental: Capsi, Capsad e Caps III, do estado de Santa Catarina. Importante destacar que o que ora é apresentado é parte de uma dissertação de mestrado que investigou, também, as características da assistência prestada pelas equipes profissionais dos serviços públicos de saúde mental referidos.

\section{Percurso metodológico}

A pesquisa é de natureza aplicada, com abordagem qualiquantitativa. Com relação aos objetivos caracteriza-se como descritiva e no que se refere aos procedimentos utilizados, trata-se de em estudo de levantamento.

Foram convidados a participar da pesquisa os 21 serviços de saúde mental cadastrados no primeiro semestre de 2013 na Secretaria de Estado da Saúde de Santa Catarina. Obteve-se retorno e anuência à participação de 19 serviços de saúde mental 
(Caps), de 9 municípios de Santa Catarina. A saber: 7 Capsi, 9 Capsad e 3 Caps III.

A escolha dos Caps deveu-se ao fato de serem os serviços estratégicos da Reforma Psiquiátrica, tendo como diretriz de atendimento ser uma base comunitária para pessoas em sofrimento psíquico. Segundo a Portaria n. ${ }^{\circ} 336 / 2002$ (BRASIL, 2002B), devem "responsabilizar-se, sob coordenação do gestor local, pela organização da demanda e da rede de cuidados em saúde mental no âmbito do seu território". Ainda, os Caps para atendimentos específicos em saúde mental para atenção em álcool e outras drogas e para crianças e adolescentes (Capsi e Capsad), possuem como critério apenas serem implantados em municípios com mais de 70 mil habitantes (BRASIL, 2002B).

Obteve-se retorno de $90,4 \%$ dos instrumentos enviados, percentual considerado significativo para o desenvolvimento da pesquisa. Mertens (2005 APUD SAMPIERI; CALLADO; LUCIO, 2013, P. 255) assevera que "uma taxa de devolução de questionários preenchidos via correio ou de maneira eletrônica acima de $50 \%$ é muito favorável".

A coleta de dados, precedida de um pré-teste para verificar a confiabilidade do instrumento, ocorreu por meio de questionário encaminhado on-line, sendo um por instituição.

Quanto à organização e à análise dos dados, as respostas aos instrumentos foram codificadas. Os dados quantitativos foram demonstrados em números, traduzindo as opiniões e informações, de modo a se proceder à análise. Os dados qualitativos foram compilados através da análise de conteúdo quantitativa, que, conforme Sampieri et al. (2013, P. 275), "é uma técnica para estudar qualquer tipo de comunicação de uma maneira 'objetiva' e sistemática, que quantifica as mensagens ou conteúdos em categorias".

A pesquisa obteve anuência de Comitê de Ética em Pesquisa da universidade a qual as autoras estão vinculadas (Parecer n. ${ }^{\circ}$ 096/13), conforme preconiza a Resolução CNS n. ${ }^{\circ} 466 / 12$ (Conep). Por meio do Termo de Consentimento Livre e Esclarecido (TCLE) on-line, encaminhado junto ao instrumento de coleta de dados, os participantes tiveram conhecimento formal e documental das condições de sua participação na pesquisa, o qual, conforme devolução do questionário respondido à pesquisadora, formalizou automaticamente o aceite dos termos previstos no TCLE. O item 9.8 do Manual Operacional para Comitês de Ética em Pesquisa, elaborado pela Comissão Nacional de Ética em Pesquisa (Conep) (BRASIL, 2002A), informa que no caso de preenchimento de questionário anônimo via e-mail, à semelhança deste estudo, a devolução do questionário preenchido configura o consentimento em participar da pesquisa. Assim, fica dispensada, nesses casos, a assinatura do Termo de Consentimento Livre e Esclarecido. Importante destacar, ainda, que o estudo não recebeu qualquer tipo de suporte financeiro e não apresentou, em qualquer de suas fases, conflito de interesse.

\section{Resultados e discussão}

Ao se analisar o conjunto dos dados coletados, observa-se que Santa Catarina tem um bom indicador de cobertura de Caps, 0,94 Caps/100.000 habitantes, quando se compara à taxa do País, que é de 0,74 Caps/100.000 habitantes (BRASIL, 2012). Verifica-se também que a modalidade com maior cobertura é de Caps I. Isto porque dentre os 295 municípios catarinenses, 277 (93,9\%) têm população de menos de 70.000 habitantes (IBGE, 2015), o que inviabiliza a implantação das demais modalidades de Caps.

Os dados coletados junto aos 19 serviços de saúde mental participantes deste estudo foram organizados em categorias definidas em consonância com os objetivos da pesquisa. Neste artigo, trata-se de uma das categorias: 'Características dos serviços de saúde mental em relação à estrutura física, recursos humanos e atendimentos ofertados'. 
A respeito do 'tempo de existência' dos serviços que participaram da pesquisa, 10 $(52,6 \%)$ apresentaram tempo de serviço maior que 7 anos; 6 (31,6\%) possuem de 4 a 6 anos; e $3(15,8 \%)$ têm entre 1 e 3 anos. Tal dado amplia a fidedignidade dos dados, uma vez que a maioria dos serviços possui significativa experiência no atendimento a pessoas com transtornos decorrentes do uso de drogas.

Quanto ao 'quantitativo de profissionais por equipes', relacionado ao número de instrumentos respondidos por Caps, obteve-se o seguinte retorno:

Respostas coletivas de 16 profissionais da equipe: 01 Caps.

Respostas coletivas de 11 profissionais da equipe: 01 Caps.

Respostas coletivas de 8 profissionais da equipe: 02 Caps.

Respostas coletivas de 5 profissionais da equipe: 01 Caps.

Resposta coletivas de 4 profissionais da equipe: 01 Caps.

Respostas coletivas de 3 profissionais da equipe: 03 Caps.

Respostas coletivas de 2 profissionais da equipe: 04 Caps.

Respostas do coordenador da equipe: 06 Caps.

Das 'categorias profissionais' que participaram da construção das respostas ao instrumento de coleta de dados das equipes, obteve-se a participação de 75 profissionais, sendo eles:

17 Psicólogos;
16 Coordenadores;

7 profissionais das categorias Terapeuta Ocupacional e Enfermeiros;

5 profissionais das categorias Assistente Social e Auxiliares Administrativos;

3 Técnicos de Enfermagem;

2 profissionais das categorias Pedagogo, Professor de Artes e Redutores de Danos;

1 profissional das categorias Farmacêutico, Auxiliar de Limpeza, Cozinheiro, Educador Físico, Educador Social (Ensino Médio), Médico Clínico Geral, Médico Psiquiatra, Motorista e Professor de Música.

No Brasil, desde a década de 1970, o trabalho em saúde passou a priorizar a composição de equipes multiprofissionais. Esse processo é dicotômico no sentido de que aumenta as possibilidades terapêuticas de assistência, contudo, pode aumentar, também, o risco de fragmentação do trabalho, impondo, assim, a necessidade de integração interdisciplinar. A atuação interdisciplinar pretende superar a fragmentação do conhecimento.

A dificuldade das equipes participantes desta pesquisa de se organizarem coletivamente para responder ao questionário denota um dos pontos críticos da integração interdisciplinar em saúde. Esse ponto refere-se à ausência de espaços para a discussão de um projeto em comum, a problemas no processo de comunicação e à existência de concepções de integralidade imprecisas e/ou equivocadas entre profissionais de saúde.

Tal fato possibilita perceber o quanto as equipes necessitam de processos de comunicação mais eficazes, que busquem compartilhar saberes e práticas, com o intuito de fortalecimento e atendimento de maneira integral. 
É possível depreender que responder ao instrumento de coleta de dados possibilitou processos comunicacionais mais complexos. Exemplo disso é a manifestação de um dos participantes:

a equipe é dividida na opinião da efetividade da redução de danos para adolescentes, assim como em qual unidade de saúde mental deveria ser atendido (Capsi ou Capsad). (Capsi 1).

Observa-se, assim, que a atuação das equipes participantes traz consigo atravessamentos complexos, pois, de um lado, emerge a necessidade de estabelecer uma base epistemológica comum entre as profissões, e, por outro, insurge a perspectiva multiprofissional e interdisciplinar proposta pela reforma psiquiátrica, que impõe a mudança do modelo de assistência, tarefa bastante complexa (VASCONCELLOS, 2010).

Com relação aos 'profissionais que compõem as equipes' das instituições participantes, pode-se verificar que os $3(15,7 \%)$ Caps III têm sua composição de equipe consoante a Portaria n. ${ }^{\circ} 336 / 2002$, que estabelece os Caps I, Caps II, Caps III, Capsi II e Capsad II e suas diretrizes (BRASIL, 2002B).

Entre os 7 Capsi participantes, 4 (21,1\%) estão de acordo com a Portaria n. ${ }^{\circ} 336 / 2002$ (BRASIL, 2002B) e 3 (15,7\%) apresentam deficiência na quantidade de profissionais de nível médio. Entre os 9 Capsad participantes, 6 (31,6\%) atendem à Portaria n. ${ }^{\circ} 336 / 2002$, e $3(15,7 \%)$ apresentam deficiências como falta de médico psiquiatra e médico clínico, enfermeiro e profissionais de nível médio.

Sobre a 'estrutura física' dos serviços, verifica-se que em 3 (15,7\%) Caps III as deficiências estão representadas pela quantidade insuficiente de quartos de repouso, quando se considera a exigência da Resolução da Anvisa - RDC n. ${ }^{\circ}$ 50, de 2002 (BRASIL, 2002C).

Os 7 (36,8\%) Capsi atendem às exigências da Resolução da Anvisa quanto à estrutura física. Entre os 9 Capsad participantes, 3 (15,7\%) apresentam deficiências com relação à sala de atendimento para desintoxicação.
Interessante é observar, ainda, que, entre os 19 serviços participantes, somente 8 $(42,1 \%)$ relataram ter sanitário adaptado para deficientes, fato que evidencia problemas de adaptação e mobilidade para pessoas com deficiências. Cabe considerar que a necessidade de superar barreiras de acesso aos serviços da Rede de Atenção à Saúde é uma das diretrizes do Decreto n. ${ }^{\circ}$ 5296, de 02 de dezembro de 2004, assim como do Decreto n. ${ }^{0}$ 7.612, de novembro de 2011, que institui o Plano Nacional dos Direitos da Pessoa com Deficiência, tornando necessária a adaptação dos serviços no tocante à estrutura física para o acolhimento de pessoas com deficiências.

Ainda, de modo a reforçar os dados apurados, destaca-se a Política Nacional de Humanização (PNH), que objetiva o aprimoramento do Sistema Único de Saúde (SUS) por meio da humanização das relações entre todos os agentes envolvidos. Uma das diretrizes da PNH é a ambiência na saúde, pois refere-se ao cuidado com o espaço físico, que possibilita os encontros social e profissional e as relações interpessoais, de modo a proporcionar atenção acolhedora, resolutiva e humana.

Há de se considerar, além disso, a ausência de alguns serviços adaptados para pessoas com deficiências, o que possivelmente prejudique a atenção acolhedora, resolutiva e humana dedicada àquelas que necessitam desses serviços.

Existe uma forte relação entre a ambiência e o cuidado, que pode ser um fator de acréscimo ou redução do cuidado.

A estrutura disponibilizada precisa oportunizar um ambiente terapêutico, e quando necessário ser passível de modificações, a fim de promover melhorias nas condições do cuidar, já que ele está presente em todas as etapas do cuidado". (WILLRICHET AL., 2013, P. 256).

Com base nesse entendimento, parece certo que a ambiência é relevante enquanto aspecto estruturante do processo terapêutico. 
Todavia, por meio dos dados apurados, observa-se que a maioria, $13(68,4 \%)$ dos Caps, atendem aos requisitos mínimos de estrutura física e recursos humanos, o que, em algumas situações, prediz a possibilidade de fragilização do atendimento em decorrência do número insuficiente de profissionais por equipes.

Os Caps funcionam sob uma lógica do território, a fim de executar as atribuições de supervisão e regulação da rede de serviços de saúde mental, e um dos objetivos desses serviços é a promoção de inserção social dos usuários através de ações intersetoriais e estratégias em conjunto para o enfrentamento dos problemas. É comum os usuários se recusarem a comparecer no Caps, seja pelo desconhecimento do serviço, por problemas de compreensão referentes à patologia, problemas socioeconômicos, entre outros.

Tal entendimento possibilita verificar a importância das 'estratégias para facilitar o acesso dos usuários' aos serviços de saúde mental. E, sob esse viés, neste estudo, encontrou-se que, entre os 19 serviços participantes, apenas 2 (10,5\%) não oferecem transporte aos usuários. Entre os 17 serviços que o disponibilizam, 7 (36,8\%) dispõem de veículo próprio do serviço e também oferecem crédito para transporte coletivo. $9(47,3 \%)$ Caps utilizam como estratégia apenas a oferta de crédito para transporte coletivo, e um Caps disponibiliza apenas o veículo da instituição.

Quanto à assistência prestada ao usuário nos Caps, a Portaria n. ${ }^{\circ}$ 336/2002 prevê que:

os pacientes assistidos em um turno (04 horas) receberão uma refeição diária; os assistidos em dois turnos (08 horas) receberão duas refeições diárias, e os que permanecerem no serviço durante 24 horas contínuas receberão 04 refeições diárias. (BRASIL, 2002B).

A respeito desse aspecto, esta pesquisa revelou que todos os serviços participantes oferecem 'refeições' aos usuários, conforme preconiza a legislação. Entretanto, 2 (10,5\%) serviços disponibilizam quantidade inferior à recomendada pela legislação vigente, o que denota o desconhecimento por parte de alguns serviços dos direitos das pessoas com transtorno mentais.

Outro dado significativo da pesquisa refere-se à 'Reunião de Equipe'. Roeder (2012) ressalta que as reuniões da equipe devem ocorrer regularmente e com integração efetiva entre os diversos setores. Para a Política Nacional de Humanização, a reunião de equipe não é apenas um espaço para divisão de tarefas, mas de diálogo, e é preciso que haja um clima democrático. Para tanto, é preciso criar um clima favorável à troca de opiniões (inclusive críticas), associado à objetividade das reuniões. Isso exige um aprendizado de todas as partes e é a primeira tarefa de qualquer equipe (BRASIL, 2009).

Ao analisar a frequência das reuniões de equipe, encontrou-se que todos os Caps participantes da pesquisa realizam reunião de equipe. Em relação à periodicidade, 12 (63,1\%) das equipes reúnem-se semanalmente e $7(36,9 \%)$ mais que 2 vezes na semana. Entre os 3 principais assuntos abordados nas reuniões de equipe, 'discussão de casos' foi indicado por $100 \%$ dos Caps; 'discussão sobre planejamento de atividades terapêuticas aos usuários' por 12 (63,1\%); e 'organização dos serviços burocráticos e rotina de trabalho' por $11(57,8 \%)$.

As discussões nas reuniões de equipe, para construção e acompanhamento do Projeto Terapêutico Singular, são oportunidades de valorização dos trabalhadores da equipe de saúde. No decorrer, vai sendo manifesta a interdependência entre todos na equipe. Tal situação favorece o cuidado com usuário e o reconhecimento do trabalho em equipe (BRASIL, 2009).

Para Vasconsellos (2010), uma efetiva interdisciplinaridade fornece espaço para um cuidado plural, no qual o usuário é o ponto comum de várias profissões e modos de cuidado. Dessa maneira, a reunião de 
equipe possibilita a transformação do cuidado ao dirimir problemas comunicacionais e de diálogo entre os profissionais e ao tornar os espaços coletivos favoráveis à elaboração dos conflitos afetivos e das fronteiras profissionais.

A ascensão da perspectiva interdisciplinar provoca mudanças nos paradigmas disciplinares e de pensamentos. Contribui para maior diálogo entre os diversos profissionais e disciplinas, para mudanças de paradigmas do pensamento, tornando-o mais criativo e sistêmico, bem como para a busca de resolução de problemas atuais e complexos (STEILL, 2011).

$\mathrm{E}$, com o intuito de filtrar os dados para os 'Caps que atendem adolescentes' com transtornos decorrentes do uso de drogas, verificou-se que, dos 19 serviços, 4 (21,05\%) Caps não atendem adolescentes, sendo $2(10,5 \%)$ na modalidade de Caps III e 2 (10,5\%) de Capsad. A justificativa para o não atendimento encontra-se no fato de no município haver Capsi ou Capsad que já acolhe essa demanda.

Destaca-se que dos 7 Capsi participantes, todos (100\%) afirmaram realizar atendimento dos adolescentes com transtornos decorrentes do uso de drogas. Cumprindo com suas características definidas na Portaria $n .^{\circ}$ 336/2002, o Capsi deve "responsabilizar-se, sob coordenação do gestor local, pela organização da demanda e da rede de cuidados em saúde mental de crianças e adolescentes no âmbito do seu território" (BRASIL, 2002B).

Um dado importante é que em 5 (55,5\%) municípios dentre os 9 onde os serviços participantes da pesquisa estão inseridos, tanto o Capsi quanto o Capsad atendem adolescentes com transtornos decorrentes do uso de drogas. Todavia, um Capsi revelou desconhecimento de que o Capsad também atende adolescentes. A situação deve ser debatida pelo sistema de garantia de proteção da criança e do adolescente para que não fira os preceitos do Estatuto da Criança e do Adolescente (ECA), Lei n. ${ }^{\circ}$ 8069, de
1990. Reitera-se que a atenção dedicada aos adolescentes deve operar em rede e por meio da articulação e da integração de diferentes atores sociais e pontos de vista, mas tendo como princípio a Proteção Integral de Crianças e Adolescentes.

Em resposta a uma pergunta 'aberta' foram citados 68 'outros serviços' voltados ao atendimento em saúde mental de adolescentes com transtornos decorrentes do uso de drogas que são oferecidos pelos municípios onde os Caps estão inseridos. Entre estes serviços, os mais citados foram: o Programa de Adolescentes em Cumprimento de Medida Socioeducativa, mencionado 13 vezes (19,11\%); a Estratégia Saúde da Família e o Hospital Geral, citados 9 vezes (13,2\%); e a Comunidade Terapêutica, referida 8 vezes (11,7\%). O Programa de Redução de Danos foi citado 3 vezes $(4,4 \%)$ dentre as 68 citações.

Importante observar que não houve menção às Unidades de Acolhimento Transitório Infantojuvenil. Há de se considerar que os municípios pesquisados possuem mais de 70 mil habitantes, sendo possível a implantação da unidade. No entanto, verifica-se que essa importante estratégia de cuidado voltada a adolescentes com transtornos decorrentes do uso de drogas ainda não é disponibilizada pelos municípios.

A assistência aos adolescentes com transtornos decorrentes do uso de drogas apresenta uma relação com os delitos cometidos pelos adolescentes. Tal afirmação é sustentada pelo fato de que o Programa de Adolescentes em Cumprimento de Medida Socioeducativa foi o mais mencionado pelos participantes da pesquisa como um serviço que atende adolescentes.

O Serviço de Proteção Social a Adolescentes em Cumprimento de Medida Socioeducativa em Meio Aberto foi tipificado pela Resolução n. ${ }^{0}$ 109/09, do Conselho Nacional de Assistência Social, como serviço de responsabilidade do Creas (Centro de Referência Especializado em Assistência Social). 
Destarte, esse dado sinaliza a relação que existe entre o uso de drogas na adolescência e o ato infracional, o que, de certo modo, sinaliza a ineficiência dos atendimentos preventivos ou realizados precocemente. $\mathrm{O}$ destaque para o Programa de Adolescentes em Cumprimento de Medida Socioeducativa como sendo de atendimento a adolescentes com transtornos decorrentes do uso de drogas denota uma possível desarticulação das políticas setoriais na efetivação das medidas socioeducativas, assim como revela o preconceito relacionado ao uso de drogas e ao ato infracional, bem como a falta de entendimento sobre as diferenças entre medidas protetivas e medidas socioeducativas.

A socioeducação é imprescindível como política pública específica para resgatar a imensa dívida histórica da sociedade brasileira com a população adolescente (vítima principal dos altos índices de violência) e como contribuição à edificação de uma sociedade justa, que zela por seus adolescentes (BRASIL, 2013). Nesse sentido, o Plano Nacional de Atendimento Socioeducativo é um passo adiante em direção a novos modos de atendimento de adolescentes autores de ato infracional e suas famílias, pois possibilita oportunidades de construção de projetos de autonomia e emancipação cidadã. Contudo, sua implantação ainda é incipiente, uma vez que esse Plano é, ao mesmo tempo, um desafio e um chamado à integração intersetorial da justiça, da saúde e da assistência social (BRASIL, 2013).

Cabe destacar aqui que algumas perspectivas contrárias possivelmente acarretem prejuízos para a atenção aos adolescentes que cometeram ato infracional, como, por exemplo, a campanha para redução da maioridade penal. É importante considerar que atos infracionais cometidos por adolescentes devem ser entendidos como resultado de circunstâncias que podem ser transformadas e superadas; e, para que exista uma inserção social saudável e de reais oportunidades, os adolescentes precisam ser protegidos de novas violências com medidas capazes de romper com a banalização da violência e seu ciclo perverso.

Sendo assim, a atuação judiciária deve coexistir com a avaliação dos profissionais socioassistenciais e de saúde que estejam na assistência com o adolescente, em meio aberto ou fechado. Por sua vez, indica-se que os profissionais não devem se ater aos fatos relacionados à prática infracional, mas às situações e à realidade de vida em que o adolescente está inserido. Tanto o ECA quanto o Sinase determinam a implementação de programas sociais e sociofamiliares destinados aos egressos do sistema socioeducativo. No entanto, observa-se que são pouco desenvolvidos.

\section{Considerações finais}

O Movimento da Reforma Psiquiátrica é um processo contínuo de assistência a pessoas em sofrimento psíquico, que deve se manter atento para não perder sua perspectiva epistemológica. Na assistência em saúde mental é preciso manter a legitimidade aos princípios do Movimento da Reforma Psiquiátrica como diretriz para o cuidado das pessoas em sofrimento psíquico. Deste modo, destaca-se que a

\section{afirmação da diferença e da singularidade hu- mana que a saúde mental, se rigorosa em seus princípios, pode extrair o vigor de suas ações e responder por aquilo que a especifica e legitima frente ao conjunto das políticas públicas. (couto;} MARTINEZ, 2007, P. 8).

O fato de $93,9 \%$ dos municípios catarinenses possuírem população de menos de 70.000 habitantes e, por tal razão neles inexistirem serviços públicos de saúde mental a adolescentes usuários de álcool e outras drogas, representa um dos desafios para a saúde mental infantojuvenil apontado por Couto, Duarte e Delgado (2008): a necessidade de estender aos Caps I, II, III, AD e aos ambulatórios de saúde mental a cobertura para tratamento de crianças e adolescentes, na ausência de recursos específicos. E, assim, 
torna-se premente a realização de pesquisas com os serviços Caps I para a compreensão de como se configura, no mesmo espaço, $o$ atendimento de crianças, adolescentes e adultos com sofrimentos psíquicos diversos.

Na pesquisa empreendida, pôde-se verificar potencialidades e fragilidades dos serviços de saúde mental participantes, como, por exemplo, que alguns apresentam esforços na busca de consolidar os princípios da reforma psiquiátrica e do SUS: universalidade, equidade e integralidade da atenção à saúde da população. Da mesma forma, foi possivel observar que os Caps participantes da pesquisa trabalham na perspectiva da atenção psicossocial, clínica ampliada, território e projetos terapêuticos singulares aos usuários do serviço.

Apesar disto, as fragilidades dos serviços pesquisados estão principalmente associadas à constituição das equipes. Isto porque os Caps participantes relatam trabalhar com o número mínimo de profissionais previsto pela Portaria n. ${ }^{\circ} 336 / 2002$. Representa ainda maior gravidade o fato de algumas equipes citarem ausência de profissionais preconizados nesta Portaria. Tal fato se repete em relação à estrutura física, pois somente os espaços mínimos consoantes à legislação vigente é que são disponibilizados aos usuários do serviço. Sobre esse aspecto, encontra-se, ainda, que alguns serviços apresentam deficiências de estrutura, principalmente no que diz respeito aos leitos para repouso, desintoxicação e adaptação para atendimentos de pessoas com deficiências.

Em se tratando de fragilidades, citam-se ainda as estratégias de acesso aos usuários, (transporte e oferta de refeições), pois dois dos Caps participantes da pesquisa não atendem ao preconizado pela Portaria n. ${ }^{0} 336 / 2002$.

Tais deficiências de recursos humanos e estruturais sinalizam a necessidade de supervisão constante dos órgãos governamentais, de modo que a qualidade, a ambiência e a efetividade do atendimento em saúde mental sejam garantidas.

Os dados apurados possibilitam constatar esforços por parte dos serviços em promover ações interdisciplinarmente, uma vez que relatam realizar reuniões semanais e que os assuntos que permeiam as reuniões dizem respeito aos atendimentos prestados e às suas relações interpessoais. Contudo, apesar dos serviços relatarem empenho para um trabalho interdisciplinar, depreende-se dificuldades quanto às reuniões da equipe. Este entendimento se baseia na resposta ao instrumento de coleta de dados de 6 Caps, onde se observou que apenas o coordenador respondeu ao instrumento. Restam, assim, dúvidas referentes à operacionalização das reuniões de equipe.

Depreende-se também a fragmentação do cuidado com os adolescentes com transtornos decorrentes do uso de drogas. Isto porque alguns Caps não têm definido se $\mathrm{o}$ atendimento deverá ser determinado pela idade ou se a avaliação da equipe é que definirá se o atendimento será realizado pelo Capsi ou pelo Capsad.

Deste modo, é notória a lacuna existente na Rede de Atenção Psicossocial, definida pela Portaria n. ${ }^{0} 3.088 / 2011$, quanto ao cuidado do adolescente com transtornos decorrentes do uso de drogas. Tal entendimento se sustenta no fato de que tanto o Capsi quanto Capsad atendem esse público, o que, consequentemente, favorece a fragmentação e a desresponsabilização pela assistência e pelo cuidado.

Nesses termos, quando o adolescente é atendido no Capsad juntamente com os adultos, observa-se uma tentativa forçada de tratá-lo como adulto. Dessa forma, possivelmente, há prejuízos ao adolescente, que apresenta características físicas, sociais e psicológicas ainda em desenvolvimento. Esse fato pode estar associado à baixa adesão dos adolescentes ao serviço e à precarização de estratégias terapêuticas desenvolvidas nos serviços, no que se refere ao atendimento juvenil.

É premente a necessidade de definição e implementação de Política de Saúde Mental específica para o atendimento de crianças e adolescentes usuários de álcool e outras drogas, bem como de ampliação dos equipamentos da rede de saúde mental para esse público.

Observa-se que ainda é incipiente a instalação de serviços especializados 
destinados ao acompanhamento continuado de crianças e adolescentes com transtornos decorrentes do uso de drogas, assim como é notória a necessidade de maior mobilização de poderes constituídos e da sociedade em torno de ações que visem à prevenção do uso de álcool e outras drogas pelo público infantojuvenil.

Destarte, considera-se que não há pretensão de se esgotar o assunto nesta pesquisa, visto que é um recorte da caracterização dos serviços de saúde mental do estado de Santa Catarina. Há necessidade de pesquisas que caracterizem o trabalho realizado nos Caps I, e é imperativo fomentar pesquisas na área da infância e da adolescência relacionadas à assistência prestada ao público portador de transtornos decorrentes do uso de drogas, de modo a fortalecer, assim, a implantação de políticas públicas eficazes.

\section{Referências}

BRASIL. Ministério da Saúde. Conselho Nacional de Saúde. Manual operacional para comitês de ética em pesquisa. Brasília, DF: Ministério da Saúde, 2002a.

Ministério da Saúde. Conselho Nacional de Saúde. Resolução no 466, de 12 de dezembro de 2012. Aprova as seguintes diretrizes e normas regulamentadoras de pesquisas envolvendo seres humanos. Diário Oficial [da] União, Brasília, DF, 12 dez. 2012. Disponível em: <http://bvsms.saude.gov.br/bvs/saudelegis/cns/2013/ res0466_12_12_2012.html>. Acesso em: 20 nov. 2015.

. Ministério da Saúde. Decreto n ${ }^{\circ} 5.296$ de 2 de dezembro de 2004. Regulamenta as Leis $\mathrm{n}^{\circ \mathrm{s}} 10.048$, de 8 de novembro de 2000, que dá prioridade de atendimento às pessoas que especifica, e 10.098, de $19 \mathrm{de}$ dezembro de 2000, que estabelece normas gerais e critérios básicos para a promoção da acessibilidade das pessoas portadoras de deficiência ou com mobilidade reduzida, e dá outras providências. Diário Oficial [da] União, Brasília, DF, 2 dez. 2004.

Ministério da Saúde. Decreto no ${ }^{\circ} .612$, de 17 de novembro de 2011. Institui o Plano Nacional dos Direitos da Pessoa com Deficiência - Plano Viver sem Limite. Brasília/DF, 2011. Diário Oficial [da] União, Brasília, DF, 17 nov. 2011a. Disponível em: <http://www. planalto.gov.br/ccivil_03/_Ato2011-2014/2011/Decreto/ D7612.htm>. Acesso em: 10 nov. 2015.

Ministério da Saúde. Portaria GM/MS nº 3.088, de 23 de dezembro de 2011. Institui a Rede de Atenção Psicossocial para pessoas com sofrimento ou transtorno mental e com necessidades decorrentes do uso de crack, álcool e outras drogas, no âmbito do Sistema Único de
Saúde (SUS). Diário Oficial [da] União, Brasília, DF, 23 dez. 2011b. Disponível em: <http://bvsms.saude.gov.br/ bvs/saudelegis/gm/2011/prt3088_23_12_2011_rep.html>. Acesso em: 10 nov. 2015.

Ministério da Saúde. Portaria GM/MS nº 336, de 19 de Fevereiro de 2002. Estabelece que os Centros de Atenção Psicossocial poderão constituir-se nas seguintes modalidades de serviços: CAPS I, CAPS II e CAPS III, definidos por ordem crescente de porte/complexidade e abrangência populacional. Diário Oficial [da] União, Brasília, DF, 9 fev. 2002b. Disponível em: <http://www.saude.mg.gov.br/images/documentos/ Portaria_336.pdf $>$. Acesso em: 10 nov. 2015.

. Ministério da Saúde. Resolução - RDC no ${ }^{\circ}$ 50, de 21 de fevereiro de 2002. Aprova o Regulamento Técnico destinado ao planejamento, programação, elaboração, avaliação e aprovação de projetos físicos de estabelecimentos assistenciais de saúde, em anexo a esta Resolução a ser observado em todo território nacional, na área pública e privada compreendendo. Diário Oficial [da] União, Brasília, DF, 21 fev. 2002c. Disponível em: <http://portal.anvisa.gov.br/wps/wcm/ connect/ca36b200474597459fc8df3fbc4c6735/RDC+ $\mathrm{N} \% \mathrm{C} 2 \% \mathrm{BA} .+50,+\mathrm{DE}+21+\mathrm{DE}+\mathrm{FEVEREIRO}+\mathrm{DE}+2002$. pdf?MOD=AJPERES $>$. Acesso em: 20 nov. 2015.

. Ministério da Saúde. Secretaria de Atenção à Saúde. Política Nacional de Humanização da Atenção e Gestão do SUS. Clínica ampliada e compartilhada. Brasília, DF: Ministério da Saúde, 2009.

. Presidência da República. Decreto Lei no 8.069, de 13 de Julho de 1990. Dispõe sobre o Estatuto da 
Criança e do Adolescente e dá outras providências. Diário Oficial [da] União, Brasília, DF, 13 jul. 1990. Disponível em: <http://www.planalto.gov.br/ccivil_03/ LEIS/L8069.htm>. Acesso em: 20 nov. 2015.

Presidência da República. Secretaria de Direitos Humanos (SDH). Plano Nacional de Atendimento Socioeducativo: diretrizes e eixos operativos para o SINASE. Brasília, DF: SDH/PR, 2013.

COUTO, M. C. V.; MARTINEZ, R. G. (Org.). Saúde mental e saúde pública: questões para a agenda da Reforma Psiquiátrica. Rio de Janeiro: UFRJ, 2007.

COUTO, M. C.; DUARTE, C. S.; DELGADO, P. G. G. A saúde mental infantil na saúde pública brasileira: situação atual e desafios. Revista Brasileira de Psiquiatria, São Paulo, v. 30, n. 4, p. 390-398, 2008.

ESPINOLA, L. L. Práticas do cuidar de adolescentes usuários de drogas. 2013. 127 f. Dissertação (Mestrado em Enfermagem) - Universidade Federal da Paraíba, João Pessoa, 2013.

\section{INSTITUTO BRASILEIRO DE GEOGRAFIA E} ESTATÍSTICA (IBGE). Pesquisa Nacional de Saúde do Escolar - 2012 (PeNSe 2012). Rio de Janeiro: IBGE, 2013.

\section{INSTITUTO BRASILEIRO DE GEOGRAFIA E}

ESTATÍSTICA (IBGE). Lista de municípios de Santa Catarina por população segundo a estimativa para 2015. Rio de Janeiro: IBGE, 2015. Disponível em: <http://cidades.ibge.gov.br/xtras/uf.php?lang $=\&$ coduf $=42 \&$ searc h=santa-catarina. Acesso em: 20 nov. 2015.

PEREIRA, Z. U. A assistência às crianças e adolescentes em uso de álcool e outras drogas nos serviços de saúde mental: da experiência clínica. In: FERREIRA, T.; BONTEMPO, V. L. (Org.). Crianças e adolescentes: o cuidado em saúde mental, o trabalho feito por muitos. Curitiba: CRV, 2012.p. 121-125.

PINSKY, I.; BESSA, M. A. Adolescência e drogas. São Paulo: Contexto, 2012.

ROEDER, M. A. Segurança sanitária: orientações para centros de atenção psicossocial. Florianópolis: Secretaria de Estado da Saúde, 2012.

SAMPIERI, R. H.; CALLADO, C. F.; LUCIO, M. P. B. Metodologia de pesquisa. 5. ed. Porto Alegre: Penso, 2013.

STEILL, A. V. Trajetória interdisciplinar formativa e profissional na sociedade do conhecimento. In: Philippi JUNIOR, A.; SILVA NETO, A. J. Interdisciplinaridade em ciência, tecnologia \&̇ inovação. Barueri: Manole, 2011. p. 209-228.

SILVA, V. A.; MATTOS, H. F. Os jovens são mais vulneráveis às drogas? In: PINSKY, I.; BESSA, M. A. Adolescência e drogas. 3. ed. São Paulo: Contexto, 2012. p. 31-44.

VASCONCELLOS, V. C. Trabalho em equipe na saúde mental: o desafio interdisciplinar em um CAPS. SMAD, Rev. Eletrônica Saúde Mental Álcool Drog., Ribeirão Preto, v. 6, n. 1, 2010. Disponível em: $<$ http://pepsic.bvsalud.org/scielo.php?script=sci_ arttext\&pid=S1806-69762010000100015\&lng=pt\&nrm =iso>. Acesso em: 16 set. 2014.

WILLRICH, J. Q. et al. Ambiência de um centro de atenção psicossocial: fator estruturante do processo terapêutico. Revista de Enfermagem da UFSM, Santa Maria, v. 3, n. 2, p. 248-258, 2013.

\footnotetext{
Recebido para publicação em junho de 2015

Versão final em setembro de 2015

Conflito de interesses: inexistente

Suporte financeiro: não houve
} 